\title{
Phytochemicals, management of diabetic peripheral neuropathy, experimental evidences
}

\begin{abstract}
Diabetic peripheral neuropathy (DPN) is an unwanted side effect that usually occurs in both types of diabetes mellitus (DM). Like other diabetic complications, the cause of DPN is not clear. This review will provide an experimental evidences on some common phytochemicals that used for the prevention or treatment of DPN. This review will not be only useful to doctors in making decisions about the best available phytochemical therapeutic choices of DPN but also to avoid the side effects of pharmacological drugs.
\end{abstract}

Keywords: diabetes mellitus, diabetic peripheral neuropathy, phytochemicals
Volume 3 Issue 5 - 2017

\author{
Hamid Saleh, Gamal S Abd El Aziz \\ Department of Anatomy, King Abdulaziz University, Saudi Arabia
}

Correspondence: Hamid Saleh, Department of Anatomy, Faculty of Medicine, King Abdulaziz University, Jeddah, Saudi Arabia, Email hsaleh@kau.edu.sa

Received: March 24, 2017 | Published: May 09, 2017

\begin{abstract}
Abbreviations: DM, diabetes mellitus; DPN, diabetic peripheral neuropathy; ROS, reactive oxygen species; GB, ginkgo biloba; MC, momordica charantia; MO, moringaoleifera; TF, trigonellafoenum; PG, punicagranatum; CP, calotropisprocera; $\mathrm{AD}$, artemisia dracunculus; CC, citrullus colocynthis; TC, tinosporacordifolia; OE, olea europaea; GS, gymnema sylvestre; CR, catharanthus roseus
\end{abstract}

\section{Introduction}

Nowadays, diabetes mellitus (DM) has become one of the most difficult health problems, where its incidence has considerably increased. It affects more than 230million people worldwide, and this number is expected to reach 350 million by $2025 .{ }^{1,2}$ Diabetic peripheral neuropathy (DPN) is the most common complication of DM. It occurs in more than $60 \%$ of the diabetic patients affecting their quality of life. The most common form of DPN is a sensory polyneuropathy with symptoms such as paresthesia, hyperalgesia and reduced temperature and vibration perceptions. ${ }^{3,4}$ Studies of DPN models have reported a decrease in impulse conduction in the peripheral nerves, interpreted as being caused by a reduction in number of large or medium-sized axons, ${ }^{5,6}$ demyelination or axon atrophy. ${ }^{7}$ Many mechanisms have been postulated in the pathogenesis of DPN including hyperglycemia, impaired insulin activity, vascular effects, hypoxia and inflammation, which leads to increased production of reactive oxygen species (ROS). $)^{3,8-10}$

It was reported that DPN is an incapacitating problem of both types of DM, which affects more than $50 \%$ of diabetic patients. ${ }^{11-13}$ However, recent studies showed that the progressive axonal atrophy is more severe in type $1 \mathrm{DM}$; in contrast to type 2, which shows nodal and para nodal degenerative changes. ${ }^{14}$ Moreover, it was reported that DPN is the leading cause of non-traumatic limb amputation ${ }^{15}$ and development of develop foot ulcers. ${ }^{16}$

Currently, DPN management depends on the conservative therapy, which includes mainly analgesics and anti-inflammatory drugs. Other approaches include neurotrophic factors and antioxidants. ${ }^{12,17,18}$ However, the clinical studies have failed to demonstrate the effectiveness of any drug treatment in improving nerve function, in addition to their wide spectrum of adverse effects which limit their usefulness. ${ }^{19,20}$
Recently, many medical professions had a significant interest regarding complementary and alternative medicine by identifying natural antidiabetic and neuro-protective agents from plant origin to replace the synthetic drugs. These plants contain a large amount of phytochemicals such as polyphenols, organosulfuric compounds, limonoids, flavonoids, terpenoids and saponins. These compounds were found to have good availability with few side effects in addition to their antioxidant activity, DNA modulation effect and immune system stimulation.

As there is a plenty of new phytochemicals from plant origin that have strong effects against the neuropathic pain and the progression DPN, this mini review is undertaken to highlight some of the phytochemical-containing plants and their experimentally potential beneficial effects.

\section{Ginkgo biloba (GB)}

Extracts of GB $(50 \mathrm{mg} / \mathrm{kg}$ body weight) exhibited neuroprotective effect on the ileum myenteric plexus and on the jejunum submucous plexus of STZ-diabetic rats. ${ }^{21}$ It is well documented that GB extract particularly inhibits oxidative stress in the mitochondria. ${ }^{22}$

\section{Momordica charantia (MC)}

It has been reported that administration of MC $(200-800 \mathrm{mg} / \mathrm{kg}$ body weight for 6 weeks) caused a decrease in withdrawal latency without impacting sensory and motor functions. ${ }^{23}$ It was demonstrated a potent neuroprotective activity of MO against neural injury and consequent neurological deficits in a diabetic mouse model. ${ }^{24}$

\section{Moringaoleifera (MO)}

The methanol extract of MO dried fruit powder has been shown to stimulate insulin release from rodent pancreatic $\beta$-cells and to inhibit cyclooxygenases and lipid peroxidation. ${ }^{25}$ The administration of 50 $100 \mathrm{mg}$ MO seed powder/kg body weight to diabetic rats has been reported to ameliorate DPN and to restore the normal histology of both kidney and pancreas. ${ }^{26}$

\section{Trigonellafoenum (TF)}

It was reported a higher GLK/glucose-6-phosphatase (G6Pase) ratio in the liver and lower levels of serum tumor necrosis factor alpha in TF-treated mice compared to controls. ${ }^{27}$ Extract from the seed of 
$\mathrm{TF}$, when administered to rats at 100 and $200 \mathrm{mg} / \mathrm{kg}$ orally for 7 days, was found to offer protection against thermal hyperalgesia, while 15 days' administration restored motor nerve conduction velocity. ${ }^{28}$

\section{Punicagranatum (PG)}

PG flower extract improved postprandial hyperglycemia in type 2 diabetes by inhibiting $\alpha$-glucosidase activity. ${ }^{29} \mathrm{PG}$ extract and its spray dried biopolymeric dispersions with casein or chitosan were evaluated against $\mathrm{DN}$ and found to be effective in improving peripheral nerve function. ${ }^{30}$

\section{Calotropisprocera (CP)}

The administration of root extract of CP at $100 \mathrm{mg} / \mathrm{kg}$ body weight in diabetic rats attenuated the impairment of diabetic condition and reversed DPN and neuropathic pain. ${ }^{31}$ Administration of methanolic and ethyl acetate extracts of the root, stem, and leaf of CP at 100 and $250 \mathrm{mg} / \mathrm{kg}$ doses for 14 days significantly attenuated hyperalgesia, tactile allodynia, and $\mathrm{HbA} 1 \mathrm{C} \%$ levels in $\mathrm{STZ}$ diabetic rats. ${ }^{32}$

\section{Artemisia dracunculus (AD)}

A study performed on high fat diet induced neuropathy of prediabetes and obesity in mice reported that the ethanolic extract of $\mathrm{AD}(500 \mathrm{mg} / \mathrm{kg} / \mathrm{d}$ for 7 weeks) normalized glycemia, alleviated nerve conduction slowing and sensory neuropathy in the peripheral nervous system. ${ }^{33}$

\section{Citrullus colocynthis (CC)}

The oral administration of $300 \mathrm{mg} / \mathrm{kg}$ body weight ethanolic extract of dried seedless pulp of CC showed insulin-tropic actions in alloxaninduced diabetic rats. ${ }^{34}$ Recently, 11-deoxocucurbitacin-glucoside was isolated from the seed of a CC chloroform fraction which exerted significant in vivo anti-inflammatory and analgesic activities at all tested doses. ${ }^{35}$

\section{Tinospora cordifolia (TC)}

Aqueous extract of TC significantly reversed the hyperalgesia at a dose of 200 and $400 \mathrm{mg} / \mathrm{kg}$ body weight. ${ }^{36}$ In addition, following TC administration, reduced glucokinase, insulin, and C-peptide levels were improved, showing the regeneration of insulin-secreting $\beta$ cells. $^{37}$

\section{Olea europaea (OE)}

Treatment with olive leaf extract ( 300 and $500 \mathrm{mg} / \mathrm{kg} / \mathrm{d}$ ) ameliorated hyperalgesia, inhibited caspase-3 activation, and decreased bcl-2likeprotein4 (Bax)/B-cell lymphoma 2 (Bcl-2) ratio. ${ }^{38}$

\section{Gymnema sylvestre (GS)}

Administration of GS extract has been shown to ameliorate the untoward effects of DPN in experimental induced diabetic rats. GS at $100 \mathrm{mg} / \mathrm{kg}$ body weight was observed to induce attenuation in diabetes-induced biochemical and histopathological alterations in the sciatic nerves of rats. ${ }^{39}$

\section{Catharanthus roseus (CR)}

The oral administration of aqueous extract $(250 \mathrm{mg} / \mathrm{kg})$ of the flowers, leaves, roots, and stems of CR and its alkaloid-free fraction $(300 \mathrm{mg} / \mathrm{kg})$ significantly reduced blood glucose in diabetic mice. Their hypoglycemic activity was comparable to that of the tolbutamide-treated group. It was demonstrated that $\mathrm{CR}$ can be used as a prophylactic agent against complications and abnormalities associated with $\mathrm{DN}^{41}$

\section{Conclusion}

In conclusion, DPN is the most annoying complication of DM. This mini review highlights some of the phytochemical-containing plants and their experimentally potential beneficial effects. The information of this review will not be only useful to doctors and patients in making decisions about the best available phytochemical therapeutic choices to improve the symptoms of DPN but also to avoid the side effects of pharmacological drugs.

\section{Acknowledgements}

None.

\section{Conflict of interest}

Author declares that there is no conflict of interest.

\section{References}

1. Kowluru RA, Chan PS. Oxidative stress and diabetic retinopathy. Exp Diabetes Res. 2007;2007:43603.

2. Yildirim Z, Ucgun NI, Kilic N, et al. Antioxidant enzymes and diabetic retinopathy. Ann N Y Acad Sci. 2007;1100:199-206.

3. Said G. Diabetic neuropathy- a review. Nat ClinPract Neurol. 2007;3(6):331-340.

4. Pinzur MS. Diabetic Peripheral Neuropathy. Foot Ankle Clin. 2011;16(2):345-349.

5. Ayaz M, Tuncer S, Okudan N, et al. Coenzyme Q(10) and alpha-lipoic acid supplementation in diabetic rats: Conduction velocity distributions. Methods Find Exp Clin Pharmacol. 2008;30(5):367-374.

6. Lennertz RC, Medler KA, Bain JL, et al. Impaired sensory nerve function and axon morphology in mice with diabetic neuropathy. J Neurophysiol. 2011;106(2):905-914.

7. Valls Canals J, Povedano M, Montero J, et al. Diabetic polyneuropathy. Axonal or demyelinating? Electromyogr Clin Neurophysiol. 2002;42(1):3-6.

8. Boulton AJ, Malik RA, Arezzo JC, et al. Diabetic somatic neuropathies. Diabetes Care. 2004;27(6):1458-1486.

9. Pop Busui R, Sima A, Stevens M. Diabetic neuropathy and oxidative stress. Diabetes Metab Res Rev. 2006;22(4):257-273.

10. Vincent AM, Callaghan BC, Smith AL, et al. Diabetic neuropathy: cellular mechanisms as therapeutic targets. Nat Rev Neurol. 2011;7(10):573-583.

11. Sima AA. New insights into the metabolic and molecular basis for diabetic neuropathy. Cell Mol Life Sci. 2003;60(11):2445-2464.

12. Tomlinson DR, Gardiner NJ. Diabetic neuropathies: components of etiology. J Peripher Nerv Syst. 2008;13(2):112-121.

13. Zochodne DW. Diabetic polyneuropathy: An update. Curr Opin Neurol. 2008;21(5):527-533

14. Sima AA, Kamiya H. Diabetic neuropathy differs in type 1 and type 2 diabetes. Ann N Y Acad Sci. 2006;1084:235-249.

15. Thomas PK. Diabetic peripheral neuropathies: their cost to patient and society and the value of knowledge of risk factors for development of interventions. Eur Neurol. 1999;41(Suppl 1):35-43.

16. Gordois A, Scuffham P, Shearer A, et al. The health care costs of diabetic peripheral neuropathy in the US. Diabetes Care. 2003;26(6):1790-1795.

17. Lee BH, Won R, Baik EJ, et al. An animal model of neuropathic pain employing injury to the sciatic nerve branches. Neuroreport. 2000;11(4):657-661. 
18. Dwight EM. The clinical management of neuropathic pain. Prog Pain Res Manag. 2006;11:30A-36A.

19. Boulton AJ, Vinik AI, Arezzo JC, et al. Diabetic neuropathies: a statement by the American Diabetes Association. Diabetes Care. 2005;28(4):956-962.

20. Habib AA, Brannagan TH. Therapeutic strategies for diabetic neuropathy Curr Neurol Neurosci Rep. 2010;10(2):92-100.

21. Da Silva GGP, Zanoni JN, Buttow NC.Neuroprotective action of Ginkgo biloba on the enteric nervous system of diabetic rats. World $J$ Gastroenterol. 2011;17(7):898-905.

22. Ahlemeyer B, Krieglstein J. Neuroprotective effects of Ginkgo biloba extract. Cell Mol Life Sci. 2003;60(9):1779-1792.

23. Malik ZA, Tabassum N, Sharma PL. Attenuation of experimentally induced diabetic neuropathy in association with reduced oxidativenitrosative stress by chronic administration of Momordicacharantia. $A d v$ Biosci Biotechnol. 2013;4(3):356-363.

24. Malik ZA, Singh M, Sharma PL. Neuroprotective effect of Momordicacharantia in global cerebral ischemia and reperfusion induced neuronal damage in diabetic mice. $J$ Ethnopharmacol. 2011;133(2):729-734

25. Francis JA, Jayaprakasam B, Olson LK, et al. Insulin secretagogues from Moringa oleifera with cyclooxygenase enzyme and lipid peroxidation inhibiting activities. Helvetica Chimica Acta. 2004;87(2):317-326.

26. Al Malki AL, El Rabey HA. The antidiabetic effect of low doses of Moringa oleifera Lam. seeds on streptozotocin induced diabetes and diabetic nephropathy in male rats. BioMed Res Int. 2015;2015:381040.

27. Yoshinari O, Igarashi K. Anti-diabetic effect of trigonelline and nicotinic acid on KK-A(y) mice. Curr Med Chem. 2010;17(20):2196-2202.

28. Morani AS, Bodhankar SL, Mohan V, et al. Ameliorative effects of standardized extract from Trigonellafoenum graecum L. seeds on painful peripheral neuropathy in rats. Asian Pac J Trop Med. 2012;5(5):385-390.

29. Li Y, Wen S, Kota BP, et al. Punica granatum flower extracts, a potent alpha-glucosidase inhibitor, improves postprandial hyperglycaemia in Zucker diabetic fatty rats. J Ethnopharmacol. 2005;99(2):239-244.

30. Raafat K, Samy W. Amelioration of diabetes and painful diabetic neuropathy by Punica granatum $L$. extract and its spray dried biopolymeric dispersions. Evid Based Complement Alternat Med. 2014;2014:180495.
31. Yadav SK, Nagori BP, Desai PK. Pharmacological characterization of different fractions of Calotropisprocera (Asclepiadaceae) in streptozotocin induced experimental model of diabetic neuropathy. $J$ Ethnopharmacol 2014;152(2):349-357.

32. Neto MCL, de Vasconcelos CFB, Thijan VN, et al. Evaluation of anti hyperglycaemic activity of Calotropis procera leaves extract on streptozotocin induced diabetes in Wistar rats. Rev Bras Farmacogn. 2013;23:913-919.

33. Watcho P, Stavniichuk R, Ribnicky DM, et al. High-fat diet-induced neuropathy of prediabetes and obesity: effect of PMI-5011, an ethanolic extract of Artemisia dracunculus L. Mediators Inflamm. 2010;2010:268547.

34. Singh LW. Traditional medicinal plants of Manipur as anti-diabetics. $J$ Med Plant Res. 2011;5(5):677-687.

35. Marzouk B, Mahjoub MA, Bouraoui A, et al. Anti inflammatory and analgesic activities of a new cucurbitacin isolated from Citrullus colocynthis seeds. Med Chem Res. 2013;22(8):3984-3990.

36. Nadig PD, Revankar RR, Detthe SM, et al. Effect of Tinospora cordifolia on experimental diabetic neuropathy. Ind $J$ Pharmacol. 2012;44(5):580-583

37. Rajalakshmi M, Eliza J, Priya CE, et al. Anti-diabetic properties of Tinospora cordifolia stem extracts on streptozotocin-induced diabetic rats. Afr J Pharma Pharmacol. 2009;3(5):71-180.

38. Kaeidi A, Esmaeili Mahani S, Sheibani V, et al. Olive (Olea europaea L.) leaf extract attenuates early diabetic neuropathic pain through prevention of high glucose-induced apoptosis: in vitro and in vivo studies. $J$ Ethnopharmacol. 2011;136(1):188-196.

39. Fatani AJ, Al Rejaie SS, Abuohashish HM, et al. Neuroprotective effects of Gymnema sylvestre on streptozotocin-induced diabetic neuropathy in rats. Exp Ther Med. 2015;9(5):1670-1678.

40. Vega Avila E, Cano Velasco JL, Alarcon Aguilar FJ, et al. Hypoglycemic activity of aqueous extracts from Catharanthus roseus. Evid Based Complement Altern Med. 2012;2012:934258.

41. Bisla G, Choudhary S, Singh E, et al. Hyperglycemia and hyperlipidemia mitigating impact of Catharanthus roseus (Sadabahar) leaves aqueous extract on type 2 diabetes mellitus subjects. Asian J Plant Sci Res. 2013;3(4):170-174. 